\title{
Study on the Reform of Computer Fashion Design Curriculum and
}

\section{Enterprise Cooperation Curriculum}

\author{
Li Guo $^{1}$ \\ ${ }^{1}$ Jiangxi Institute of Fashion Technology, Nanchang Jiangxi, 330201
}

\section{KEYWORDS: Costume Design Courses; Teaching Model; Business Cooperation}

\begin{abstract}
Theory with practice is the new era of a new model of teaching, but also to meet the requirements of the times, in this mode can not only improve students' practical ability, but also can improve improve the overall quality of students. In Teaching and the market, social, enterprise combining requirements, computer fashion design course and establish business cooperation with the course, which is a new teaching model that allows students to get exercise, learning to real practical knowledge.
\end{abstract}

\section{Introduction}

The traditional costume design courses, students do not have practical things like cloth, can only operate through the computer simulation of the students, presented on a computer screen design is abstract, in the actual design of each encounter a wide variety of issues, and the computer will issue only idealized. The teacher told you how to do drawing, design software, a large part of the time spent on learning software time, the focus has shifted to learn, learning to learn true knowledge is limited and unsatisfactory results.

How to reform after the fashion design course, students need to learn in the school of theoretical knowledge, to lay a solid foundation, and then went on to cooperate with the school class business practices, clothing design in the real sentiment of actual production, learning and experienced designers in line with market demand and the ideal apparel products. This school is not learned, such reform is a concrete manifestation of a combination of engineering, to enable students to jump out of the textbook, out of the theory, learning in practice, the actual process to learn.

Traditional teaching methods greatly limits the ability of students to practical operation, only theoretical knowledge to students on the books is not enough services and enterprises, and therefore lower curriculum reform in vocational education, school-enterprise cooperation needs, students from the school into the business better. Trained students generally more solid theoretical basis, if a good hands-on training, so in the future work will get better development. Computer costume design more attention to the trend of the times, our textbooks are often behind the actual production, thus requiring students to keep up with the pace of the times, to learn to master the theoretical knowledge but also practical experience.

\section{The Reform of the Content}

In today's situation, the university set up a computer in the fashion design course has been unable to meet market demand. Graduates into the business process can not be quickly integrated into the production process going, the cost of business will increase, criticized the school's training mode, so to meet the business line of the course, the requirements of social reform is imminent. 
Changing the concept: traditional teaching costume design courses is also paying more attention to cultivating students 'innovative thinking in the actual teaching of teachers to develop students' imagination and divergent thinking, and this is going to inherit and carry forward. But in the traditional teaching mode, there are many drawbacks, teaching concept is still lagging behind, not daring to innovate new teaching methods and conservative. Therefore, in teaching to change the existing concept behind, and actively explore new teaching model, keeping up with market demand, business demand, timely changes in teaching philosophy, students apply their knowledge.

Curriculum reform: according to the needs of enterprises to set the course content, already eliminated, backward traditional teaching content should be promptly replaced and updated, the purpose of vocational education is to cultivate applied talents can provide business services. For example, in the production of garment enterprises generally have to go through these processes, the design - the plate - making sample - modify - production, each process in the classroom school education to combine these processes, focusing on linking theory with practice, and will not let the classroom change It was empty and meaningless. Schools keep their own cooperative enterprises to establish a two-way course content that is in full accordance with the requirements of enterprise creation, finally arranged by the company internship. In the teaching content in the fine is not much in the real is not imaginary, it is possible to serve the enterprises can improve students' self-worth.

Reform teaching methods: on your computer fashion design class, the general practice side edge way of teaching large teaching. Such teaching methods belong to instill education, teachers are not able to know the students' learning, students do not fully understand all the teachers, the formation of a fuzzy concept. So to change teaching methods, costume design on the computer class, the teacher can allow students to design their own clothing explain, to express their design ideas and perspectives, teachers can design their own clothing for students to evaluate, a good place to be commended, not the place to make appropriate recommendations. Enable students to become masters of the classroom, allowing students to become masters of learning. Each student is different design concepts and teachers should combine their views on student work reasonable, objective evaluation, this evaluation is not only encouraged but also a promoter.

Reform Evaluation System: The evaluation system is a concrete reflection of the overall teaching and learning outcomes. To establish a scientific and rational evaluation system is the most important curriculum reform, schools should cooperate with enterprises, the enterprises and teachers to score, for example, fashion design creativity, design, plate, whether the mainstream of the times, and so were scoring, the last named outstanding works reward, low scores on the works to propose amendments. Good design work, of course there is a market demand, which also reflects the "production", "learning", "research" requirements. This evaluation system is not fixed, with the market and business requirements change, allowing students and teachers in the teaching process in keeping with the times demand to change their curriculum to promote fashion design for the better direction.

Reform Textbooks: textbook is the soul of teaching. A backward, not kept pace only scripted teaching students, the school came out, we can not understand what businesses need and social need, which requires the curriculum reform must first textbook reform. Cooperation with the school business, to them outstanding costume design, costume design, costume design, etc. to form a complete system and incorporated into the materials used in student learning. And add specific examples in textbooks allow students to study fashion design course at the forefront of the times.

\section{The Development of Content}


The school should seize the advantages of their own talent, and actively establish training bases and enterprises to establish long-term cooperation, to ensure that their talents have made great progress. To fully consider the significance of the students to encourage personnel transport venture.

While schools should establish their own R \& D base and business, to achieve true "production", "learning", "research" model schools to fully stand in the perspective of personnel training thinking, in order to ensure the long-term culture of clothing design talent to improve solid foundation.

Some hold more lectures, lectures, so that students feel the latest developments in the international top level design and cutting-edge design in the campus.

Students' creative thinking inspiration and schools can work with business and want to get corporate sponsorship, allow students out of the problem, more to the practice of life to find inspiration.

Schools also need to cooperate more with business and communication in curriculum reform, so that the formation of the integration of research, it is not bound by time and space.

\section{Conclusion}

"Production", "learning", "research" integration is a new model now school personnel training, curriculum reform of computer costume design is in line with this requirement. Closed out of the classroom, into the enterprise and social production to not only enhance the overall quality of students, but also to become a social enterprise needs talent. Reform of Computer Course and costume design business cooperation program is in line with the requirements under the reform era, the theory of education is a key step toward the practical education.

\section{References}

[1] Chen Xia, Gao Yifeng. Fashion Design Course System Reform in Higher Vocational School-Enterprise Cooperation Mode [J]. Nantong Vocational University, 2014,01: 47-50.

[2] Sun Di, Chen Xue. Colleges Clothing Vocational Design Research Reform and Practice [J]. Jilin Province Economic Management Cadre College, 2014,01: 108-111.

[3] Dare Reform And Practice Of Vocational Fashion Design Courses Combination Of Engineering [J]. Education And Vocation, 2008,36: 113-115.

[4] Lao Yueming. Costume Design Course-Reform Of "Independent Cooperative Learning" [A]. Minjiang University, Tainan University Of Technology, The European Fashion Trends Association Of China R \& D Center (IDA) 2012 Artistic Engineering And Creativity Industry International Conference Proceedings [C]. Minjiang University, Tainan University of Technology, The European Fashion Trends In China R \& D Center Association (IDA): 2012:. 4. 